\title{
Satisfaction with control of systemic lupus erythematosus and lupus nephritis: physician and patient perspectives
}

This article was published in the following Dove Press journal:

Patient Preference and Adherence

4 October 2016

Number of times this article has been viewed

\author{
Neelufar Mozaffarian' \\ Steve Lobosco ${ }^{2}$ \\ Peng $\mathrm{Lu}^{3}$ \\ Adam Roughley ${ }^{2}$ \\ Gabriela Alperovich ${ }^{4}$ \\ 'Clinical Development, AbbVie Inc., \\ North Chicago, USA; ${ }^{2}$ Adelphi Real \\ World Ltd., Macclesfield, UK; \\ ${ }^{3}$ Clinical Development, AbbVie Inc., \\ Worcester, MA, USA; ${ }^{4} \mathrm{Global}$ Medical \\ Affairs Immunology, AbbVie Inc., \\ Madrid, Spain
}

Purpose: Patient satisfaction with disease control of systemic lupus erythematosus (SLE) is an important component of medical management. This analysis evaluated patient and physician satisfaction with disease control of SLE, factors associated with satisfaction/dissatisfaction, and the degree of physician-patient concordance of these parameters.

Patients and methods: Data were extracted from the US Adelphi Real World Lupus Disease Specific Programme ${ }^{\circledR}$, a cross-sectional survey of 50 rheumatologists, 25 nephrologists, and their patients with non-nephritis SLE (NNSLE) or lupus nephritis (LN).

Results: Physicians reported moderate or severe disease activity in $25.0 \%$ of patients with NNSLE and in $50.5 \%$ of patients with LN, and were satisfied with disease control in $78.6 \%$ $(132 / 168)$ and $73.8 \%(152 / 206)$ of patients, respectively. For patients, $75.8 \%(75 / 99)$ with NNSLE were satisfied with their current treatment, compared with $65.5 \%$ (74/113) with LN. Physician-patient agreement (70.7\%) on the level of satisfaction was "slight" (kappa $=0.1445$ ) for NNSLE; patients were more frequently dissatisfied than physicians with regard to joint tenderness, fatigue, anxiety, pain on movement, malar rash, and photosensitivity. Physician-patient agreement $(71.4 \%)$ on the level of satisfaction was "fair" (kappa $=0.3695)$ for LN; patients expressed greater dissatisfaction than physicians for headache, photosensitivity, and anxiety, whereas physicians were more dissatisfied with regard to joint swelling, kidney function, and blood pressure control. In general, patients with NNSLE or LN who were dissatisfied (or whose physicians were dissatisfied) were more likely to have joint swelling, joint stiffness, malar rash, hair loss, depression, and fatigue, have moderate or severe disease, or to be currently experiencing disease flare.

Conclusion: These data highlight the patient and physician dissatisfaction with real-world disease control of SLE.

Keywords: lupus, satisfaction, concordance, agreement, disease control

\section{Introduction}

Systemic lupus erythematosus (SLE) is a chronic, relapsing-remitting autoimmune disease that can affect multiple organs and presents with a wide range of signs and symptoms. The prevalence of SLE has been reported to be 53 cases per 100,000 persons in the US, ${ }^{1}$ although this may be an underestimate due to underdiagnosis of the disease. ${ }^{2,3}$ At least one-half of all patients with SLE may experience lupus nephritis (LN) at some time during their disease course, although this number may be even higher because autopsy results show some renal involvement in most patients with SLE. ${ }^{4} \mathrm{LN}$ is a poor prognostic factor and may result in renal dysfunction and increased morbidity and mortality.
Correspondence: Steve Lobosco Adelphi Real World Ltd., Adelphi Mill, Grimshaw Lane, SKI0 5JB Bollington, Cheshire, UK

Tel +44I625 577233

Fax +44I625 575853

Email steve.lobosco@adelphigroup.com 
There is no curative treatment for SLE. Current options considered to be standard-of-care include three major groups of pharmacotherapies: antimalarials, glucocorticoids, and synthetic immunosuppressants. More recently, biologic agents, including belimumab and rituximab, have been used to treat patients with SLE. ${ }^{5,6}$ However, only belimumab is specifically approved for use in SLE, and there is a need for additional treatment options.

Symptoms of lupus can impact multiple aspects of a patient's well-being. ${ }^{7,8}$ Therefore, symptomatic control and maintenance of function and quality of life are particularly important in the management of patients with lupus. ${ }^{9}$ A study of patients with SLE in the US found a positive association between overall satisfaction with medical care and healthrelated quality of life. ${ }^{10}$ Another study in patients with lupus highlighted the relationship between satisfaction with medical care and depression. ${ }^{11}$ There may be discordance between physician and patient perceptions of disease status, which may be driven by patients experiencing both psychological and physical symptoms versus physicians evaluating solely the physical manifestations and other comorbidities of the disease. ${ }^{12,13}$

There is a paucity of data regarding levels and drivers of patient- and physician-reported satisfaction with disease control in SLE and on the concordance between patients and their physicians with respect to satisfaction with lupus treatment. Using a cohort of patients with SLE in the US (with and without LN), the current analysis determined levels of patient and physician satisfaction with disease control and examined the degree of physician-patient agreement with respect to treatment satisfaction.

\section{Materials and methods}

Data were drawn from the US Adelphi Lupus Disease Specific Programme (DSP ${ }^{\circledR}$ ), a real-world survey of lupus patients and their specialist physicians (US rheumatologists or nephrologists) between December 2009 and May 2010. The research was conducted in full accordance with the US Health Insurance Portability and Accountability Act 1996 (HIPAA; www.hhs.gov/ocr/privacy/). No ethical approval was obtained. This is not required for a survey of this nature (multi-sponsored) as stipulated in HIPAA guidelines.

\section{Physician recruitment and eligibility}

Physicians were required to see five or more patients with non-nephritis SLE (NNSLE; rheumatologists) or LN (nephrologists) in their clinics in a typical month and to be actively involved in the management of the patient's disease. Physicians meeting these criteria were asked to report on the next five consecutive patients with lupus, presenting for any reason, via completion of a patient record form (PRF). The PRF included data on disease severity, associated symptoms and concomitant physical and psychological conditions, treatment history, and current therapy.

Patients for whom the physician completed a PRF were asked to fill out a patient self-completion (PSC) questionnaire, which included data on general health, lupus history, symptoms, and medications. Written informed consent was collected for all respondents.

\section{Satisfaction with disease control}

Physicians and patients were asked to report their satisfaction with SLE disease control using a 3-point scale: $1=$ satisfied; $2=$ not satisfied, but I believe this is the best that can be realistically achieved; and $3=$ not satisfied, and I believe better control can be achieved. Responses were recorded in the PRF and PSC questionnaires, respectively, and comparisons were made between respondents in these three satisfaction categories.

\section{Patient-reported fatigue}

Fatigue was evaluated using the validated Functional Assessment of Chronic Illness Therapy (FACIT) Fatigue Scale ${ }^{14}$ as part of the PSC. FACIT scores range from 0 to 52, with lower scores indicating more fatigue. Patients scored fatigue over the previous 7 days.

\section{Patient-reported feelings about SLE}

Patients' feelings regarding their SLE were assessed using a 10-point Likert scale (ranging from 0 [completely disagree] to 10 [completely agree]) for the following nine nonvalidated statements: "Overall, my lupus is a major problem in everyday life"; "I know my condition well and have learned to manage it over a long period of time"; "I am always keen to try the next new treatment for lupus"; "I will ask my doctor about any new treatments which become available"; "I am very concerned about the possible side effects of treatment"; "My social life has gotten worse since getting lupus"; "I worry all the time about having a flare up of my lupus"; "I have never felt calm or peaceful since getting lupus"; and "I always feel downhearted and depressed because of my lupus".

\section{Populations for analysis}

The DSP data were derived from the forms completed by the physicians and patients; as physicians and patients could forego answering individual questions, the number of respondents differed for individual questions and for certain 
analyses. Therefore, the population (or base) is given for each individual analysis whenever appropriate and indicates the number of respondents (physicians or patients) who provided responses to that item.

\section{Statistical analyses}

Statistical analyses were performed using Stata version 12.1 (StataCorp LP, College Station, TX, USA). Descriptive statistics are presented throughout (mean and standard deviation [SD] for continuous variables; frequency and percentage for categorical variables); associated $P$-values were derived using an analysis of variance, chi-square test, and KruskalWallis test as appropriate.

A concordance analysis was conducted to evaluate agreement between patient- and physician-reported treatment satisfaction using the kappa statistic. The level of concordance was categorized according to Landis and Koch, ${ }^{15}$ with a kappa statistic of $<0$ indicating no agreement; $0-0.20$, slight agreement; $0.21-0.40$, fair agreement; $0.41-0.60$, moderate agreement; 0.61-0.80, substantial agreement; and 0.81-1.0, almost perfect agreement.

\section{Results \\ Demographics}

The survey cohort consisted of 374 patients for whom physician-reported satisfaction data were available (NNSLE, n=168; LN, n=206); patient-reported satisfaction data were obtained from 212 patients (NNSLE, $n=99$; LN, $\mathrm{n}=113$ ). A total of 75 physicians (50 rheumatologists and 25 nephrologists) participated in the survey.

Table 1 shows the demographic and disease characteristics of the patient population. The mean age of the survey population was 43.5 years for patients with NNSLE and 39.4 years for patients with LN; the majority of patients in both groups were female (NNSLE, 95.2\%; LN, 88.8\%). A higher proportion of patients with LN than with NNSLE were reported to have severe disease (physician-reported, 10.7\% vs $4.2 \%$; patient-reported, $9.2 \%$ vs $2.7 \%$ ). Significantly higher proportions of patients with NNSLE had fibromyalgia and Sjögren's syndrome (11.0\% and $11.7 \%$, respectively) compared with patients with LN (5.1\% and 4.1\%), whereas significantly higher proportions of patients with LN had high blood pressure and anemia (29.4\% and 28.9\%) compared with patients with NNSLE $(13.6 \%$ and $9.7 \% ; P<0.05$ for all comparisons). A significantly higher proportion of patients with NNSLE than with LN received antimalarial drugs (69.0\% vs $41.9 \%, P<0.001)$; and a significantly higher proportion of patients with LN than with NNSLE received immunosuppressants $(66.5 \%$ vs $38.7 \%, P<0.001)$ or steroids (76.4\% vs $53.6 \%, P<0.001)$.

\section{Overall satisfaction reported by patients and physicians}

When patients with NNSLE and LN were analyzed together, the overall proportion of patients satisfied with SLE management was high and was comparable in both the patient $(70.3 \%)$ and physician $(75.9 \%)$ groups. Nevertheless, a higher proportion of patients, compared with the physician group, were "not satisfied but believed this was the best that could be realistically achieved". A higher proportion of physicians, compared with the patient group, were "not satisfied and believed better control could be achieved" (Table 2).

\section{Satisfaction reported by patients with NNSLE and LN}

Among patients with NNSLE, 75.8\% (75/99) were satisfied with their current treatment, whereas 17.2\% (17/99) were "not satisfied with the current level of disease control but believed this was the best that could be achieved". The remaining 7.1\% (7/99) were "not satisfied and believed a better level of control could be achieved".

More patients with NNSLE in the "satisfied" group had mild disease compared with the "not satisfied" groups $(P=0.004$ across groups for patient-reported severity; Table 3). Significantly greater proportions of patients in the "not satisfied" groups had disease flare (patient-reported, $P=0.005$; physician-reported, $P=0.031$; Table 3 ) compared with the "satisfied" group. Significant positive associations were observed between patient-reported dissatisfaction and symptoms of joint tenderness, joint stiffness, joint swelling, pain on movement, malar rash, depression, anxiety, fatigue, hair loss, and photosensitivity (Figure 1A). Patients in the "not satisfied" categories reported greater severity of joint stiffness $(P=0.009)$. There were no significant associations between satisfaction with disease control and age, gender, ethnicity, or employment status (data not shown).

Patients with NNSLE who were dissatisfied with their current level of disease control also reported greater levels of fatigue (mean FACIT-Fatigue scores of 40.7 in the "satisfied" group, 29.4 in the "not satisfied, but I believe this is the best that can be realistically achieved" group, and 28.3 in the "not satisfied, and I believe better control can be achieved" group; $P<0.001$ across groups).

Patients with NNSLE who were dissatisfied with their current level of disease control were more likely to view 
Table I Demographic and clinical characteristics of NNSLE and LN patient cohorts

\begin{tabular}{|c|c|c|c|}
\hline Characteristic & $\begin{array}{l}\text { Patients with } \\
\text { NNSLE } n=168\end{array}$ & $\begin{array}{l}\text { Patients with } \\
\text { LN n=206 }\end{array}$ & $\begin{array}{l}\text { P-value } \\
\text { NNSLE vs LN }\end{array}$ \\
\hline Mean (SD) age, years & $43.5(14.9)$ & $39.4(13.1)$ & 0.005 \\
\hline Females, $\mathrm{n}(\%)$ & $160(95.2)$ & $182(88.8)^{\mathrm{a}}$ & 0.037 \\
\hline Ethnicity, n (\%) & $\mathrm{n}=167$ & $\mathrm{n}=205$ & \\
\hline White & I0I (60.5) & $85(4 I .5)$ & $<0.001$ \\
\hline Black/Afro-Caribbean & $37(22.2)$ & $70(34.1)$ & 0.012 \\
\hline Hispanic/Latino & $21(12.6)$ & $28(13.7)$ & 0.878 \\
\hline Chinese & $3(1.8)$ & $10(4.9)$ & 0.156 \\
\hline Asian subcontinent & $2(1.2)$ & $7(3.4)$ & 0.195 \\
\hline Asian other & $\mathrm{I}(0.6)$ & $3(1.5)$ & 0.631 \\
\hline Other & $2(1.2)$ & $2(1.0)$ & 1.000 \\
\hline Employment status, ${ }^{\mathrm{b}} \mathrm{n}(\%)$ & $\mathrm{n}=167$ & $\mathrm{n}=206$ & \\
\hline Full time & $70(41.9)$ & $69(33.5)$ & 0.107 \\
\hline Part time & $20(12.0)$ & $27(13.1)$ & 0.757 \\
\hline Self-employed & $3(1.8)$ & $2(1.0)$ & 0.660 \\
\hline Unemployed & $21(12.6)$ & $53(25.7)$ & 0.002 \\
\hline Student & $12(7.2)$ & $9(4.4)$ & 0.265 \\
\hline Current smoker, n (\%) & $22 / 161(13.7)$ & $15 / 186(8.1)$ & 0.116 \\
\hline Mean (SD) time since diagnosis, years & $5.9(7.0)$ & $5.6(6.5)$ & 0.702 \\
\hline Current physician-reported lupus disease severity, n (\%) & & & $<0.001$ \\
\hline Mild & $126(75.0)$ & $102(49.5)$ & \\
\hline Moderate & $35(20.8)$ & $82(39.8)$ & \\
\hline Severe & $7(4.2)$ & $22(10.7)$ & \\
\hline Current patient-reported lupus disease severity, n (\%) & $n=111$ & $n=120$ & 0.008 \\
\hline Mild & $75(67.6)$ & $62(51.7)$ & \\
\hline Moderate & $33(29.7)$ & $47(39.2)$ & \\
\hline Severe & $3(2.7)$ & II (9.2) & \\
\hline Current physician-reported symptoms, $n$ (\%) & $\mathrm{n}=154$ & $n=197$ & \\
\hline Joint tenderness & $56(36.4)$ & $65(33.0)$ & 0.572 \\
\hline Joint stiffness & $58(37.7)$ & $85(43.1)$ & 0.325 \\
\hline Joint swelling & $31(20.1)$ & $43(21.8)$ & 0.792 \\
\hline Pain on movement & $35(22.7)$ & $46(23.4)$ & 0.899 \\
\hline Pain at rest & $26(16.9)$ & $20(10.2)$ & 0.079 \\
\hline Chronic pain & $13(8.4)$ & $20(10.2)$ & 0.713 \\
\hline Fibromyalgia & $17(11.0)$ & $10(5.1)$ & 0.044 \\
\hline Osteoarthritis & $18(11.7)$ & $15(7.6)$ & 0.203 \\
\hline Malar or butterfly rash & $19(12.3)$ & $33(16.1)$ & 0.290 \\
\hline Discoid rash & II (7.I) & $22(11.2)$ & 0.268 \\
\hline High blood pressure & $21(13.6)$ & $58(29.4)$ & 0.001 \\
\hline Depression & $27(17.5)$ & $39(19.8)$ & 0.680 \\
\hline Anxiety & $28(18.2)$ & $32(16.2)$ & 0.670 \\
\hline Kidney dysfunction/impairment & $4(2.6)$ & $121(61.4)$ & $<\mathbf{0 . 0 0 1}$ \\
\hline Headaches/migraine & $12(7.8)$ & $20(10.2)$ & 0.576 \\
\hline Fatigue & $56(36.4)$ & $63(32.0)$ & 0.427 \\
\hline Hair loss & $17(11.0)$ & $23(11.7)$ & 0.868 \\
\hline Photosensitivity & $18(11.7)$ & $34(17.3)$ & 0.173 \\
\hline Anemia & $15(9.7)$ & $57(28.9)$ & $<\mathbf{0 . 0 0 1}$ \\
\hline Thrombocytopenia & $10(6.5)$ & $20(10.2)$ & 0.253 \\
\hline Leukopenia & $17(11.0)$ & $21(10.7)$ & 1.000 \\
\hline Sjögren's syndrome & $18(11.7)$ & $8(4 . I)$ & 0.008 \\
\hline Current medications, $\mathrm{n}(\%)$ & $n=168$ & $\mathrm{n}=203$ & \\
\hline Antimalarial & $116(69.0)$ & $85(41.9)$ & $<\mathbf{0 . 0 0 1}$ \\
\hline Immunosuppressant & $65(38.7)$ & $135(66.5)$ & $<\mathbf{0 . 0 0 1}$ \\
\hline Biologic DMARD & $\mathrm{I}(0.6)$ & $3(1.5)$ & 0.630 \\
\hline Traditional NSAID & $48(28.6)$ & $34(16.7)$ & 0.008 \\
\hline COX-2 inhibitor & $15(8.9)$ & $24(11.8)$ & 0.399 \\
\hline Corticosteroid & $90(53.6)$ & $155(76.4)$ & $<0.001$ \\
\hline Other ${ }^{c}$ & $29(17.3)$ & $46(22.7)$ & NS \\
\hline
\end{tabular}


Table I (Continued)

\begin{tabular}{llll}
\hline Characteristic & Patients with & Patients with & P-value \\
& NNSLE n=168 & LN n=206 & NNSLE vs LN \\
\hline $\begin{array}{l}\text { Currently in physician-reported remission, n (\%) } \\
\text { Currently in disease flare, } \mathrm{n}(\%)\end{array}$ & $93 / 166(56.0)$ & $123 / 203(60.6)$ & 0.397 \\
$\quad$ & & & \\
Physician-reported & $20 / 168(11.9)$ & $20 / 204(9.8)$ & 0.614 \\
Patient-reported & $17 / 106(16.0)$ & $10 / 115(8.7)$ & 0.105 \\
\hline
\end{tabular}

Notes: ${ }^{\mathrm{N}} \mathrm{N}=205$, ${ }^{\mathrm{b}}$ Categories not shown: unemployed due to lupus, retired, and homemaker, Included prescriptions for 14 other classes of medication. Bold indicates that the $P$-value is statistically significant.

Abbreviations: COX, cyclooxygenase; DMARD, disease-modifying antirheumatic drug; LN, lupus nephritis; NNSLE, non-nephritis systemic lupus erythematosus; NS, nonsignificant; NSAID, nonsteroidal anti-inflammatory drug.

their lupus as "a major problem in everyday life" $(P=0.002$ across groups), to feel that their "social life has gotten worse since getting lupus" ( $P=0.006$ across groups), to worry about "having a flare" ( $P=0.017$ across groups), and to feel "downhearted and depressed" because of their lupus ( $P=0.017$ across groups). No other significant findings were associated with the remaining statements (data not shown).

Among patients with LN, 65.5\% (74/113) were satisfied with their current treatment, 30.1\% (34/113) responded "not satisfied, but I believe this is the best that can be realistically achieved," and 4.4\% (5/113) responded "not satisfied, and I believe better control can be achieved".

In the LN group, significant associations were noted between patient-reported satisfaction and age; patients who were satisfied (mean age, 38.7 years) and patients who were "not satisfied but believed this was the best that could be realistically achieved" (mean age, 43.2 years) were similar in age but were older than patients who were "not satisfied and believed better control could be achieved" (mean age, 25.6 years; $P=0.01$; Table 3 ). Significant inverse associations were noted between patient-reported satisfaction and physician- and patient-reported disease severity $(P<0.001$ across groups for each). Significant positive associations were noted for patient-reported dissatisfaction and current joint tenderness, joint stiffness, pain on movement, anxiety, headaches/migraines, and fatigue (Figure 1B). Patients in the "not satisfied" categories reported greater severity of malar rash $(P=0.035)$. The mean number of treatments was higher among patients in the "not satisfied" categories compared with those who were satisfied ( $P=0.009$ across groups). There were no significant associations between satisfaction with disease control and ethnicity, smoking status, or time since diagnosis (data not shown).

Patients with LN who were "not satisfied" with their current disease control also reported greater levels of fatigue (mean FACIT-Fatigue scores of 39.3 in the "satisfied" group, 25.9 in the "not satisfied, but I believe this is the best that can be realistically achieved" group, and 35.6 in the "not satisfied, and I believe better control can be achieved" group; $P<0.001$ across groups).

Patients with LN in either of the "not satisfied" categories were more likely to view their lupus as "a major problem in everyday life" ( $P<0.001$ across groups) and feel that their "social life has gotten worse since getting lupus" $(P=0.04$ across groups). No other significant findings were associated with the remaining statements (data not shown).

\section{Satisfaction reported by physicians for patients with NNSLE and LN}

Rheumatologists were satisfied with disease control in $78.6 \%$ of their patients with NNSLE (132/168), dissatisfied but felt the level of control was the best they could achieve for $8.9 \%$ of their patients $(15 / 168)$, and dissatisfied and believed that better control could be achieved for $12.5 \%$ of their patients $(21 / 168)$.

Rheumatologists who were "not satisfied" with disease control in patients with NNSLE were more likely to be managing patients who were unemployed ( $P=0.043$ across groups; data not shown), who had moderate or severe disease ( $P<0.001$ across groups), or who were currently experiencing disease flare (physician- and patient-reported; $P<0.001$ across groups for both; Table 4). They were less likely to be

Table 2 Satisfaction levels for all patients and physicians (NNSLE + LN)

\begin{tabular}{|c|c|c|c|c|}
\hline & Satisfied n (\%) & $\begin{array}{l}\text { Not satisfied } \\
\text { (best achieved)a n (\%) }^{\text {(best }}\end{array}$ & $\begin{array}{l}\text { Not satisfied } \\
\text { (could be better) }^{\mathrm{b}} \text { n (\%) }\end{array}$ & Total $\mathbf{N}$ \\
\hline Patient-reported satisfaction & $149(70.3)$ & $5 I(24.1)$ & $12(5.7)$ & 212 \\
\hline Physician-reported satisfaction & $284(75.9)$ & $51(13.6)$ & $39(10.4)$ & 374 \\
\hline
\end{tabular}

Notes: aNot satisfied, but I believe this is the best that can be realistically achieved, ${ }^{b}$ Not satisfied, and I believe better control can be achieved. Abbreviations: LN, lupus nephritis; NNSLE, non-nephritis systemic lupus erythematosus. 
Table 3 Associations between patient-reported satisfaction and NNSLE and LN cohort characteristics

\begin{tabular}{|c|c|c|c|c|c|c|c|c|}
\hline \multirow[t]{2}{*}{ Characteristic } & \multicolumn{3}{|c|}{ Patients with NNSLE } & \multirow[t]{2}{*}{$P$-value } & \multicolumn{3}{|c|}{ Patients with LN } & \multirow[t]{2}{*}{$P$-value } \\
\hline & $\begin{array}{l}\text { Satisfied } \\
n=75\end{array}$ & $\begin{array}{l}\text { Not satisfied } \\
\text { (best achieved) }^{a} \\
n=17\end{array}$ & $\begin{array}{l}\text { Not satisfied } \\
\text { (could be } \\
\text { better) }^{b} n=7\end{array}$ & & $\begin{array}{l}\text { Satisfied } \\
n=74\end{array}$ & $\begin{array}{l}\text { Not satisfied } \\
\text { (best achieved) } \\
n=34\end{array}$ & $\begin{array}{l}\text { Not satisfied } \\
\text { (could be } \\
\text { better) }^{b} n=5\end{array}$ & \\
\hline Mean (SD) age, years & $40.9(14.8)$ & $44.6(15.6)$ & 45.4 (I5.7) & 0.524 & $38.7(13.1)$ & $43.2(12.7)$ & $25.6(8.1)$ & 0.013 \\
\hline Females, \% & 94.7 & 100 & 85.7 & 0.339 & 87.7 & 94.1 & 20.0 & $<0.001$ \\
\hline $\begin{array}{l}\text { Mean (SD) time since } \\
\text { diagnosis, years }\end{array}$ & $4.3(4.4)$ & $7.1(6.9)$ & $3.7(6.1)$ & 0.114 & $5.7(6.2)$ & $7.0(7.7)$ & $4.3(4.2)$ & 0.549 \\
\hline $\begin{array}{l}\text { Current physician-reported } \\
\text { lupus severity, \% }\end{array}$ & & & & 0.111 & & & & $<0.001$ \\
\hline Mild & 80.0 & 70.6 & 42.9 & & 59.5 & 35.3 & 0.0 & \\
\hline Moderate & 16.0 & 29.4 & 57.1 & & 36.5 & 35.3 & 40.0 & \\
\hline Severe & 4.0 & 0 & 0 & & 4.1 & 29.4 & 60.0 & \\
\hline $\begin{array}{l}\text { Current patient-reported } \\
\text { lupus severity, \% }\end{array}$ & & & & 0.004 & & & & $<0.001$ \\
\hline Mild & 73.3 & 41.2 & 28.6 & & 63.5 & 30.3 & 20.0 & \\
\hline Moderate & 25.3 & 52.9 & 57.1 & & 33.8 & 51.5 & 0.0 & \\
\hline Severe & 1.3 & 5.9 & 14.3 & & 2.7 & 18.2 & 80.0 & \\
\hline $\begin{array}{l}\text { Currently in physician- } \\
\text { reported remission, \% }\end{array}$ & 60.8 & 52.9 & 0 & 0.008 & 65.8 & 50.0 & 40.0 & 0.197 \\
\hline Currently in disease flare, $\%$ & & & & & & & & \\
\hline Physician-reported & 10.7 & 5.9 & 42.9 & 0.031 & 12.3 & 8.8 & 40.0 & 0.144 \\
\hline Patient-reported & 11.0 & 23.5 & 57.1 & 0.005 & 7.0 & 12.5 & 40.0 & 0.055 \\
\hline
\end{tabular}

Notes: aNot satisfied, but I believe this is the best that can be realistically achieved, ${ }^{b}$ Not satisfied, and I believe better control can be achieved. Bold indicates that the $P$-value is statistically significant.

Abbreviations: LN, lupus nephritis; NNSLE, non-nephritis systemic lupus erythematosus; SD, standard deviation.

managing patients who were currently in remission $(P<0.001$ across groups).

Rheumatologists "not satisfied" with the level of disease control in patients with NNSLE reported that their patients had more joint tenderness, joint stiffness, joint swelling, pain on movement, pain at rest, fibromyalgia, leukopenia, hair loss, depression, and fatigue (Figure 2A). Significant positive associations were observed for the severity of physicianreported joint stiffness and physician dissatisfaction with disease control $(P=0.005)$.

For their patients with LN, nephrologists were satisfied with disease control in 73.8\% (152/206), "dissatisfied but believed this was the best that could be achieved" in $17.5 \%$ (36/206), and "dissatisfied and believed better control could be achieved" for $8.7 \%(18 / 206)$.

Compared with nephrologists who were "satisfied", nephrologists who were "not satisfied" with disease control in their patients with $\mathrm{LN}$ were more likely to be managing patients who were female $(P=0.044)$, who had moderate or severe disease (physician- and patient-reported; $P<0.001$ for both), who were currently experiencing disease flare (physician- and patient-reported; $P<0.001$ for both), and who were less likely to be in physician-reported remission $(P<0.001$; Table 4$)$.

Malar rash, discoid rash, kidney dysfunction, thrombocytopenia, and leukopenia were more frequent in patients with LN of the "not satisfied" physician groups (Figure 2B). Joint swelling and hair loss were factors in the "not satisfied and better could be achieved" group only. No significant associations were observed across the physician-reported satisfaction categories in relation to symptom severity.

\section{Concordance of treatment satisfaction between patients with NNSLE and their physicians}

Agreement between patients with NNSLE (N=99) and rheumatologists for the level of satisfaction with current disease control was "slight" $(70.7 \%$; kappa $=0.1445)$. The level of agreement varied significantly with NNSLE severity $(P=0.0062)$, with the greatest agreement observed for mild NNSLE (59/75; 78.7\%). Physician-patient agreement on the level of satisfaction also tended to decrease $(P=0.2035)$ as the number of medications taken by patients with NNSLE increased: 1 drug, 22/27 (81.5\%); 2 drugs, 22/30 (73.3\%); and $\geq 3$ drugs, $26 / 42$ (61.9\%); NNSLE severity was positively associated with an increased number of medications $(P<0.001)$.

Few dissatisfied patients with NNSLE and their physicians perceived a possibility for improvement: $17 \%$ of patients felt their level of control was the best that could be achieved and $7 \%$ felt that improvement was possible; whereas 
A

NNSLE

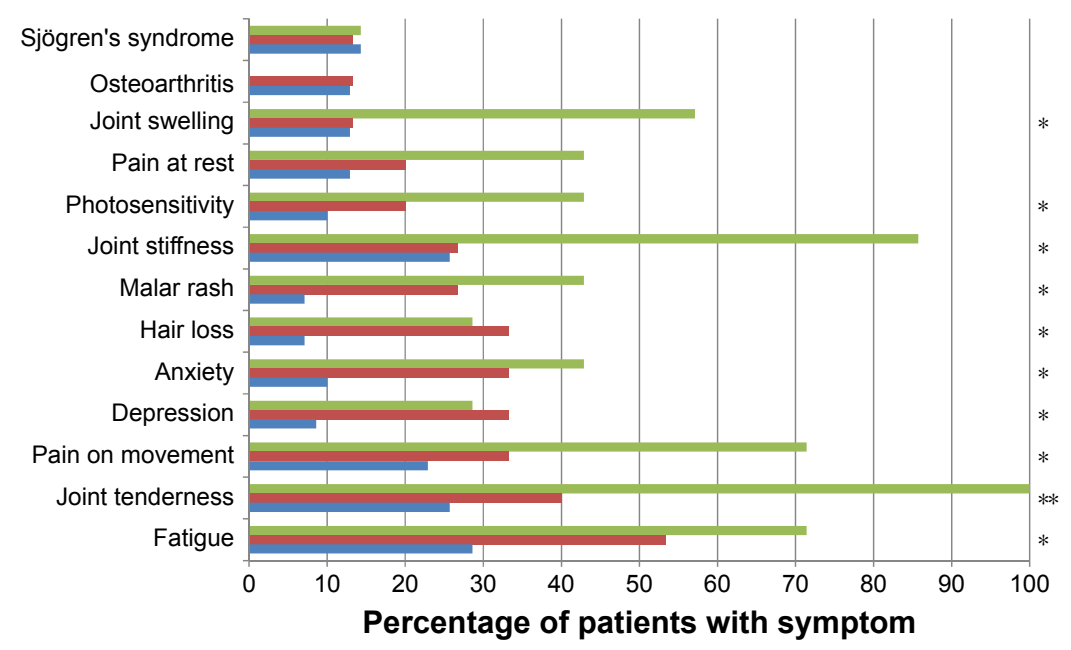

Not satisfied (could be better; $n=7)^{\mathrm{a}} \quad$ Not satisfied (best achieved; $\left.n=15\right)^{\mathrm{b}} \quad$ Satisfied $(n=70)$

\section{B}

LN

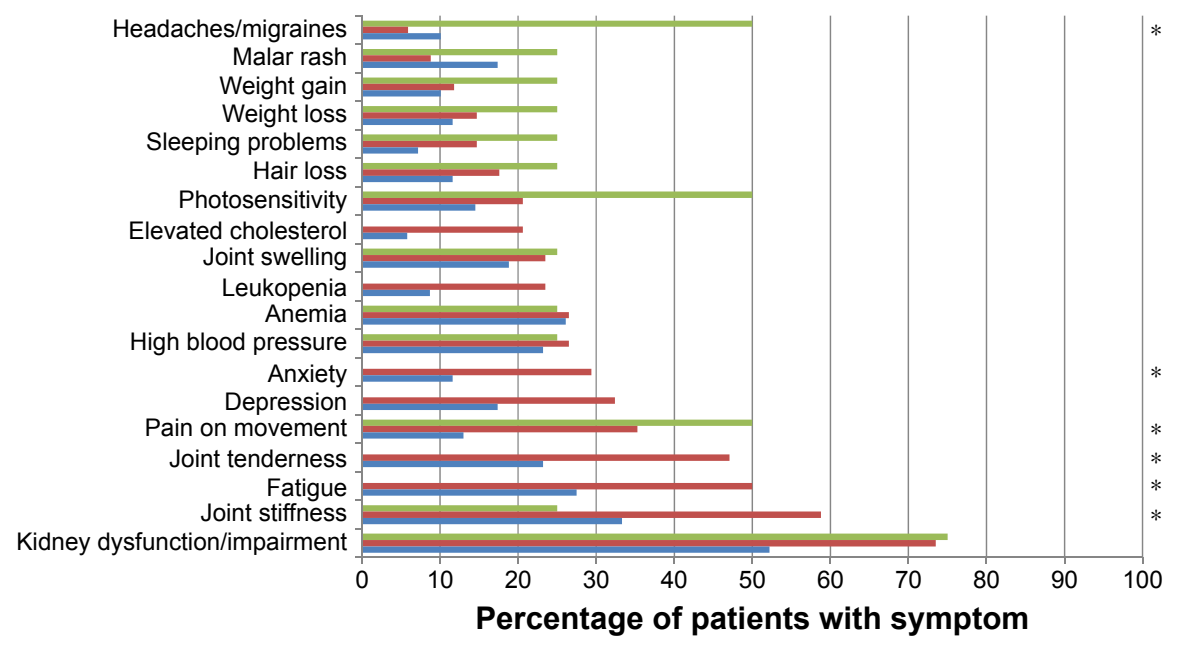

Not satisfied (could be better; $n=4)^{a} \quad$ Not satisfied (best achieved; $\left.n=34\right)^{b} \quad$ Satisfied $(n=69)$

Figure I Patient-reported satisfaction in relation to the presence of lupus symptoms in $\geq 10 \%$ of patients with NNSLE (A) and LN (B).

Notes: $* P<0.05 ; * * P<0.00$ I, ${ }^{a}$ Not satisfied, and I believe better control can be achieved, ${ }^{b}$ Not satisfied, but I believe this is the best that can be realistically achieved.

Abbreviations: LN, lupus nephritis; NNSLE, non-nephritis systemic lupus erythematosus.

$1 \%$ of physicians indicated that this was the best they could achieve for their patients, and $12 \%$ felt that improvement was possible.

\section{Concordance of treatment satisfaction between patients with $\mathrm{LN}$ and their physicians}

Agreement between patients with LN $(\mathrm{N}=112)$ and nephrologists for satisfaction with current disease control was "fair" (71.4\%; kappa $=0.3695)$. Patient - physician agreement on satisfaction tended to be higher $(P=0.0740)$ in patients with mild $(42 / 56 ; 75.0 \%)$ or moderate $(31 / 41$; $75.6 \%) \mathrm{LN}$ compared with severe LN (7/15; 46.7\%). As the number of medications taken by patients with LN increased, physician-patient agreement on the level of satisfaction tended to decrease $(P=0.0764): 1$ drug, $17 / 20(85.0 \%)$; 2 drugs, 30/39 (76.9\%); and $\geq 3$ drugs, $31 / 51$ (60.8\%). The number of medications increased with the severity of LN, but did not achieve statistical significance $(P=0.051)$.

Few dissatisfied patients with LN and their physicians perceived a possibility for improvement: $30 \%$ of patients felt their level of disease control was the best that could 
Table 4 Associations between physician-reported satisfaction and NNSLE and LN cohort characteristics

\begin{tabular}{|c|c|c|c|c|c|c|c|c|}
\hline \multirow[t]{2}{*}{ Characteristic } & \multicolumn{3}{|c|}{ Patients with NNSLE } & \multirow[t]{2}{*}{$P$-value } & \multicolumn{3}{|c|}{ Patients with LN } & \multirow[t]{2}{*}{$\overline{P \text {-value }}$} \\
\hline & $\begin{array}{l}\text { Satisfied } \\
n=132\end{array}$ & $\begin{array}{l}\text { Not satisfied } \\
\text { (best achieved) }^{a} \\
n=15\end{array}$ & $\begin{array}{l}\text { Not satisfied } \\
\text { (could be } \\
\text { better) }^{b} n=2 \text { I }\end{array}$ & & $\begin{array}{l}\text { Satisfied } \\
n=I 52\end{array}$ & $\begin{array}{l}\text { Not satisfied } \\
\text { (best achieved) }^{a} \\
n=36\end{array}$ & $\begin{array}{l}\text { Not satisfied } \\
\text { (could be } \\
\text { better) }^{\mathrm{b}} \mathrm{n}=18\end{array}$ & \\
\hline Mean (SD) age, years & $44.0(15.4)$ & 43.5 (II.7) & $40.5(14.3)$ & 0.608 & $39.3(13.5)$ & $41.7(10.6)$ & $35.2(13.2)$ & 0.237 \\
\hline Females, $\%$ & 94.7 & 100 & 95.2 & 0.659 & 91.4 & 86.1 & 72.2 & 0.044 \\
\hline $\begin{array}{l}\text { Mean }(\mathrm{SD}) \text { time since } \\
\text { diagnosis, years }\end{array}$ & $6.3(7.5)$ & $5.7(5.3)$ & $3.9(4.0)$ & 0.354 & $5.4(6.4)$ & $6.1(5.9)$ & $6.8(8.1)$ & 0.603 \\
\hline $\begin{array}{l}\text { Current physician-reported } \\
\text { lupus severity, \% }\end{array}$ & & & & $<0.001$ & & & & $<0.001$ \\
\hline Mild & 87.9 & 26.7 & 28.6 & & 58.6 & 33.3 & 5.6 & \\
\hline Moderate & 10.6 & 60.0 & 57.1 & & 35.5 & 52.8 & 50.0 & \\
\hline Severe & 1.5 & 13.3 & 14.3 & & 5.9 & 13.9 & 44.4 & \\
\hline $\begin{array}{l}\text { Current patient-reported } \\
\text { lupus severity, \% }\end{array}$ & & & & 0.002 & & & & $<0.001$ \\
\hline Mild & 74.2 & 50.0 & 25.0 & & 59.8 & 42.9 & 8.3 & \\
\hline Moderate & 23.7 & 50.0 & 66.7 & & 37.9 & 42.9 & 41.7 & \\
\hline Severe & 2.2 & 0 & 8.3 & & 2.3 & 14.3 & 50.0 & \\
\hline $\begin{array}{l}\text { Currently in physician- } \\
\text { reported remission, \% }\end{array}$ & 68.5 & 26.7 & 0 & $<0.001$ & 69.3 & 45.7 & 16.7 & $<0.001$ \\
\hline Currently in disease flare, $\%$ & & & & & & & & \\
\hline Physician-reported & 6.1 & 33.3 & 33.3 & $<0.001$ & 5.3 & 11.4 & 44.4 & $<0.001$ \\
\hline Patient-reported & 9.0 & 80.0 & 41.7 & $<0.001$ & 4.8 & 5.0 & 41.7 & $<0.001$ \\
\hline
\end{tabular}

Notes: ${ }^{a}$ Not satisfied, but I believe this is the best that can be realistically achieved, ${ }^{b}$ Not satisfied, and I believe better control can be achieved. Bold indicates that the $P$-value is statistically significant.

Abbreviations: LN, lupus nephritis; NNSLE, non-nephritis systemic lupus erythematosus; SD, standard deviation.

be achieved, and $4 \%$ felt that improvement was possible; whereas $17 \%$ of physicians indicated that this was the best they could achieve for their patients, and $9 \%$ felt that improvement was possible.

\section{Discussion}

These data demonstrated that substantial levels of both physician- and patient-reported dissatisfaction exist with SLE disease control in the US. For NNSLE, $20 \%$ of rheumatologists and $25 \%$ of patients were dissatisfied with the current level of disease control, consistent with a previous survey in which $79.0 \%$ of physicians and $73.3 \%$ of patients reported treatment satisfaction. ${ }^{16}$ For rheumatologists and their patients with NNSLE, dissatisfaction with disease control was associated with disease severity, disease activity (lack of remission and presence of current flare), as well as joint symptoms, pain, malar rash, depression, anxiety, and fatigue. For $\mathrm{LN}, \sim 33 \%$ of nephrologists and $25 \%$ of patients were dissatisfied; physician- and patient-reported dissatisfaction was associated with the severity of $\mathrm{LN}$ and various signs and symptoms of disease.

Contrary to a previous survey that reported moderate agreement between patient and physician assessment, ${ }^{16}$ concordance between patient- and physician-reported satisfaction in our survey was only "slight" among those with NNSLE and "fair" among those with LN. For patients with NNSLE, discordance between patients and physicians was mainly associated with physician-reported disease activity (moderate or severe) and with patient-reported disease flare. For patients with LN, patient-physician discordance was associated with the presence of disease flare (both patient- and physicianreported). Interestingly, among patients with either NNSLE or LN who were in physician-defined remission, physicians tended to be more satisfied with the level of disease control than their patients. Patients with NNSLE who have selfreported disease flares show a lower level of satisfaction with disease control than their physicians, highlighting a need to assess patient perceptions of disease in addition to clinical and laboratory assessments. These data are consistent with a previous report showing discordant assessments of disease activity among patients with NNSLE and their physicians. ${ }^{17}$ Patients with NNSLE and LN were more likely to be dissatisfied than their physicians, which could impact treatment adherence and overall well-being. ${ }^{18,19}$

Negative perceptions of illness have implications for overall disease burden. In our survey, patients dissatisfied with their level of disease control also had a negative perception of the possibility for improvement. A study of adults with SLE in Australia found that negative perceptions of disease were associated with a higher psychological burden and 
A

NNSLE

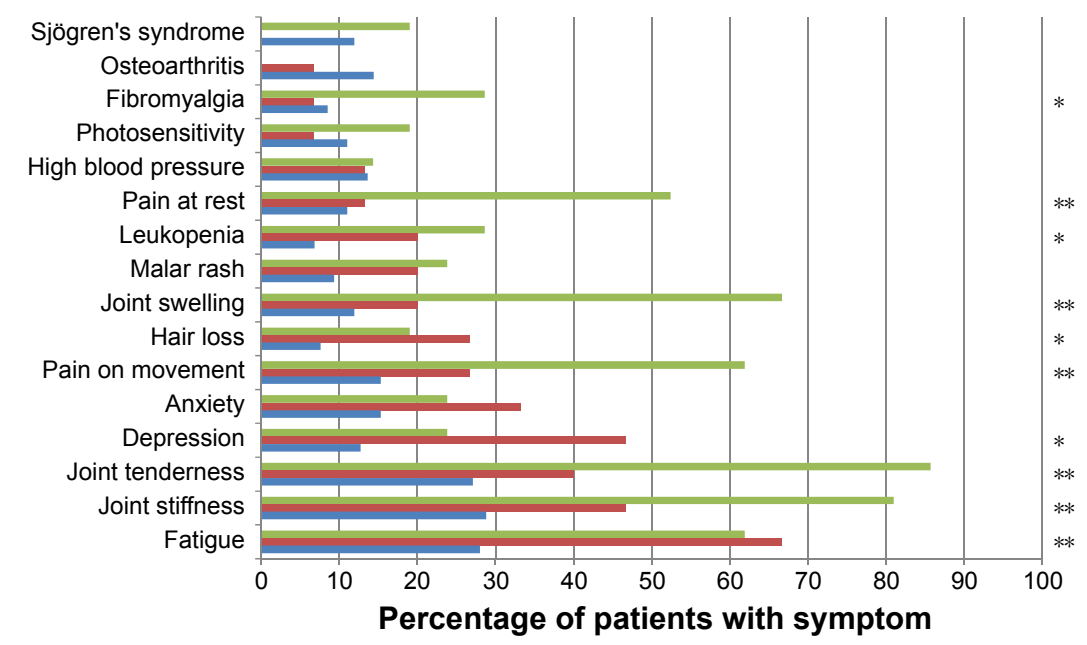

Not satisfied (could be better; $n=21)^{\mathrm{a}} \quad$ Not satisfied (best achieved; $\left.n=15\right)^{\mathrm{b}} \quad \square$ Satisfied $(n=118)$

B

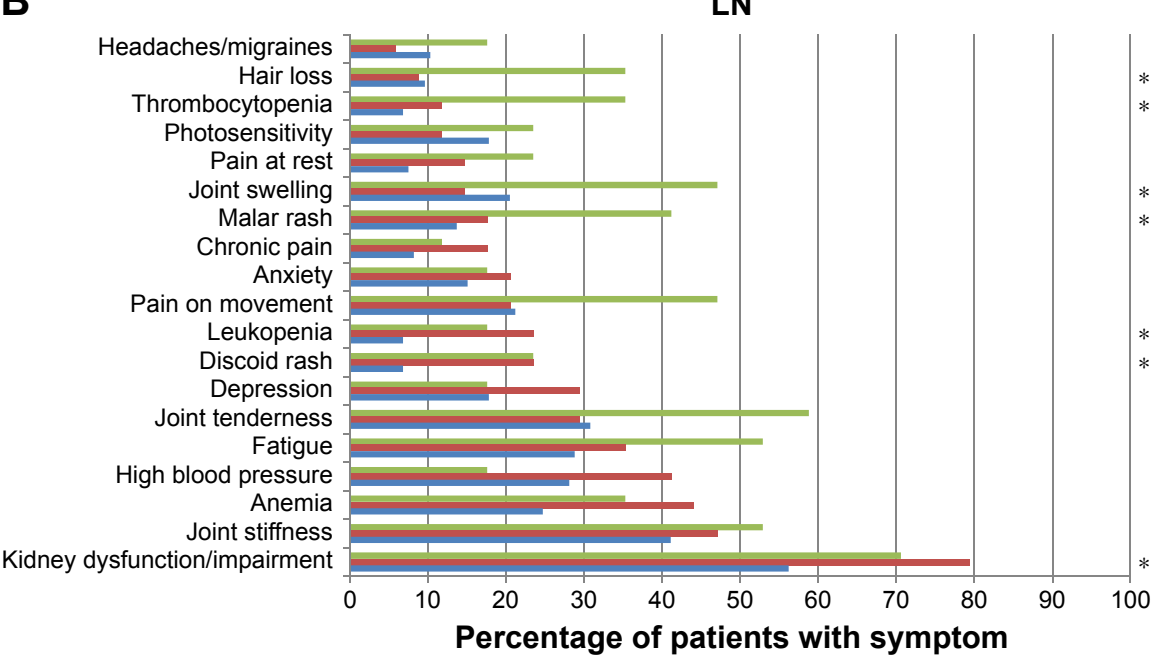

Not satisfied (could be better; $n=17)^{\mathrm{a}} \square$ Not satisfied (best achieved; $\left.n=34\right)^{\mathrm{b}} \quad$ Satisfied $(n=146)$

Figure 2 Physician-reported satisfaction in relation to the presence of lupus symptoms in $\geq 10 \%$ of patients with NNSLE (A) and LN (B).

Notes: $* P<0.05 ; * * P<0.00$ I. ${ }^{a}$ Not satisfied, and I believe better control can be achieved, ${ }^{b}$ Not satisfied, but I believe this is the best that can be realistically achieved.

Abbreviations: LN, lupus nephritis; NNSLE, non-nephritis systemic lupus erythematosus.

symptoms of depression. ${ }^{11}$ Because data suggest that depression and anxiety may exacerbate SLE, ${ }^{20}$ patients should be routinely questioned about depression, anxiety, and fatigue in addition to the physical symptoms of lupus.

Physicians dissatisfied with treatment control in NNSLE had a perception of greater potential for improvement $(1 \%$ felt the control was the best that could be achieved and $12 \%$ felt that improvement was possible) than dissatisfied physicians of patients with LN (17\% indicated that control was the best they could achieve and $9 \%$ felt that further improvements were possible), suggesting a greater unmet treatment need in LN.
This study identified factors associated with treatment satisfaction and determined the level of concordance/discordance among patients with SLE and their physicians. We observed that physicians and patients associate different factors with satisfactory control of SLE. In a previous report of 208 females with lupus, patients tended to score their disease activity based on both physical and psychological factors, whereas physicians tended to base their assessments on clinical signs and symptoms. ${ }^{13}$ Such discrepancies in disease perception have implications for treatment goals and treatment adherence, and highlight the need to utilize patient self-assessment in addition to accepted clinical outcome 
measures. Furthermore, our results support the need for improved understanding between physicians and patients with respect to their perceptions of SLE and satisfaction with treatments and outcomes. A recent study evaluating disease perception by patients with SLE and final-year medical students found significant differences between these groups; medical students, compared with patients, perceived SLE to be significantly more threatening (ie, less controllable, with higher burden of symptoms and emotional response). ${ }^{21}$

This study has limitations associated with survey-based and retrospective methodology. Assessment of disease activity by physicians depended on their professional judgment; only 21 of 375 patients included in the analysis had documented SLE Disease Activity Index scores. Medication use also could have affected the results. The "not satisfied" groups had relatively small numbers of patients; thus, further studies are needed to verify "slight" or "fair" concordance observed between patients and physicians. A high proportion of patients in the LN group were treated with steroids, suggesting that future studies might analyze satisfaction stratified by steroid dose. While we noted correspondences between various disease parameters and treatment satisfaction, cause and effect could not be established, although a cross-sectional survey of adults with SLE in the US has shown that steroid use was significantly associated with reduced patient satisfaction. ${ }^{22}$ Despite its limitations, the current study is more likely to represent "real-world" findings than a controlled clinical trial. Additionally, this study provides the patient's perspective, which is usually missing in clinical trials. We believe that further research is needed to identify the underlying drivers of treatment dissatisfaction in patients with SLE and their physicians. Furthermore, the clinical implications of the discordance in treatment satisfaction between physicians and their patients and of the association between treatment dissatisfaction and disease symptoms will need to be further investigated in future studies.

Although the current treat-to-target recommendations state the importance of shared decisions between informed patients and their physicians, a clear definition of key patientreported outcomes in SLE is still pending and is not part of the treat-to-target recommendations, ${ }^{23}$ thus reinforcing the need to find a way to include patient preferences in disease management. The results of this survey highlight the considerable levels of dissatisfaction with disease control among patients with NNSLE and LN and their physicians in the US, as well as the discordance in treatment satisfaction between physicians and their patients, especially in severe, difficult-to-manage
SLE. Our results also suggest that interventions to identify and address comorbid symptoms, such as anxiety, depression, and fatigue, may have a significant impact on reducing patient-perceived disease burden and enhancing patient satisfaction with treatment. A patient-centric approach, which includes the patient's perspectives and preferences during treatment, could become part of the standard management of SLE as it might help to improve the physician-patient relationship and, consequently, contribute to improving patient satisfaction and quality of care.

\section{Acknowledgments}

The authors thank the physicians and patients who took part in this research. Medical writing assistance was provided by Tracey Lonergan, PhD, of Adelphi Real World Ltd, and Michael J Theisen, PhD, and Natalia Zhukovskaya, PhD, of Complete Publication Solutions, LLC (North Wales, PA, USA). This support was funded by AbbVie.

\section{Author contributions}

SL and AR participated in acquisition and analysis of the data. NM, GA, and PL participated in analyzing and interpreting the data and were involved in writing and revising the manuscript. All authors were involved in revising critically for intellectual content, gave final approval of the version to be published, and agree to be accountable for this work.

\section{Disclosure}

SL and AR are employed by Adelphi Real World Ltd. GA is an AbbVie employee. NM was employed by AbbVie at the time of the research and is currently employed by Gilead Sciences, Inc. PL was employed by AbbVie at the time of the research and is currently employed by Shire Plc. The authors report no other conflicts of interest in this work.

\section{References}

1. Danchenko N, Satia JA, Anthony MS. Epidemiology of systemic lupus erythematosus: a comparison of worldwide disease burden. Lupus. 2006; 15(5):308-318

2. Geva E, Lerner-Geva L, Burke M, Vardinon N, Lessing JB, Amit A. Undiagnosed systemic lupus erythematosus in a cohort of infertile women. Am J Reprod Immunol. 2004;51(5):336-340.

3. Spinillo A, Beneventi F, Ramoni V, et al. Prevalence and significance of previously undiagnosed rheumatic diseases in pregnancy. Ann Rheum Dis. 2012;71(6):918-923.

4. Jindal B, Joshi K, Radotra BD, Banerjee AK. Fatal complications of systemic lupus erythematosus - an autopsy study from north India. Indian J Pathol Microbiol. 2000;43(3):311-317.

5. Leszczynski P, Pawlak-Bus K. New treatment strategy including biological agents in patients with systemic lupus erythematosus. Pol Arch Med Wewn. 2013;123(9):482-490.

6. Benlysta ${ }^{\circledR}$ (belimumab). Full prescribing information. MD: GlaxoSmithKline Rockville, Inc; 2015. 
7. Mok CC, Ho LY, Cheung MY, Yu KL, To CH. Effect of disease activity and damage on quality of life in patients with systemic lupus erythematosus: a 2-year prospective study. Scand J Rheumatol. 2009;38(2): 121-127.

8. Pettersson S, Lovgren M, Eriksson LE, et al. An exploration of patient-reported symptoms in systemic lupus erythematosus and the relationship to health-related quality of life. Scand J Rheumatol. 2012;41(5):383-390.

9. Thumboo J, Strand V. Health-related quality of life in patients with systemic lupus erythematosus: an update. Ann Acad Med Singapore. 2007;36(2):115-122

10. Dua AB, Aggarwal R, Mikolaitis RA, Sequeira W, Block JA, Jolly M. Rheumatologists' quality of care for lupus: comparison between a university and county hospital. Arthritis Care Res (Hoboken). 2012;64(8) 1261-1264.

11. Philip EJ, Lindner H, Lederman L. Relationship of illness perceptions with depression among individuals diagnosed with lupus. Depress Anxiety. 2009;26(6):575-582.

12. Neville C, Clarke AE, Joseph L, Belisle P, Ferland D, Fortin PR. Learning from discordance in patient and physician global assessments of systemic lupus erythematosus disease activity. J Rheumatol. 2000;27(3): 675-679.

13. Yen JC, Abrahamowicz M, Dobkin PL, Clarke AE, Battista RN, Fortin PR. Determinants of discordance between patients and physicians in their assessment of lupus disease activity. J Rheumatol. 2003; 30(9):1967-1976.

14. Yellen SB, Cella DF, Webster K, Blendowski C, Kaplan E. Measuring fatigue and other anemia-related symptoms with the functional assessment of cancer therapy (FACT) measurement system. J Pain Symptom Manage. 1997;13(2):63-74.
15. Landis JR, Koch GG. The measurement of observer agreement for categorical data. Biometrics. 1977;33(1):159-174.

16. Strand V, Galateanu C, Pushparajah DS, et al. Limitations of current treatments for systemic lupus erythematosus: a patient and physician survey. Lupus. 2013;22(8):819-826.

17. Leong KP, Chong EY, Kong KO, et al. Discordant assessment of lupus activity between patients and their physicians: the Singapore experience. Lupus. 2010;19(1):100-106.

18. Garcia Popa-Lisseanu MG, Greisinger A, Richardson M, et al. Determinants of treatment adherence in ethnically diverse, economically disadvantaged patients with rheumatic disease. J Rheumatol. 2005;32(5): 913-919.

19. Sutcliffe N, Clarke AE, Levinton C, Frost C, Gordon C, Isenberg DA. Associates of health status in patients with systemic lupus erythematosus. J Rheumatol. 1999;26(11):2352-2356.

20. Adams SG Jr, Dammers PM, Saia TL, Brantley PJ, Gaydos GR. Stress, depression, and anxiety predict average symptom severity and daily symptom fluctuation in systemic lupus erythematosus. J Behav Med. 1994;17(5):459-477.

21. Nowicka-Sauer K, Pietrzykowska M, Banaszkiewicz D, Hajduk A, Czuszynska Z, Smolenska Z. How do patients and doctors-to-be perceive systemic lupus erythematosus? Rheumatol Int. 2016;36(5):725-729.

22. Beusterien K, Bell JA, Grinspan J, Utset TO, Kan H, Narayanan S. Physician-patient interactions and outcomes in systemic lupus erythematosus (SLE): a conceptual model. Lupus. 2013;22(10):1038-1045.

23. van Vollenhoven RF, Mosca M, Bertsias G, et al. Treat-to-target in systemic lupus erythematosus: recommendations from an international task force. Ann Rheum Dis. 2014;73(6):958-967.
Patient Preference and Adherence

\section{Publish your work in this journal}

Patient Preference and Adherence is an international, peer-reviewed, open access journal that focuses on the growing importance of patient preference and adherence throughout the therapeutic continuum. Patient satisfaction, acceptability, quality of life, compliance, persistence and their role in developing new therapeutic modalities and compounds to optimize

\section{Dovepress}

clinical outcomes for existing disease states are major areas of interest for the journal. This journal has been accepted for indexing on PubMed Central. The manuscript management system is completely online and includes a very quick and fair peer-review system, which is all easy to use. Visit http://www. dovepress.com/testimonials.php to read real quotes from published authors. 